\title{
Influence of Partial Substitution of Fe by Mn on the Thermomagnetic Properties of Magnetocaloric $\mathrm{LaFe}_{11.2} \mathrm{Co}_{0.7} \mathrm{Si}_{1.1}$ Alloy
}

\author{
P. GęBARA ${ }^{a, *}$ AND J. MARCIN ${ }^{b}$ \\ ${ }^{a}$ Institute of Physics, Częstochowa University of Technology, Armii Krajowej 19, 42-200 Częstochowa, Poland \\ ${ }^{b}$ Institute of Experimental Physics, Slovak Academy of Sciences, Watsonova 47, 04001 Košice, Slovakia \\ The aim of this paper was to study the influence of partial substitution of $\mathrm{Fe}$ by $\mathrm{Mn}$ in the \\ $\mathrm{LaFe}_{11.2-x} \mathrm{Mn}_{x} \mathrm{Co}_{0.7} \mathrm{Si}_{1.1}$ (where $x=0.1,0.2$ and 0.3) alloys. Measurements revealed that a systematic increase of \\ $\mathrm{Mn}$ in the alloy composition resulted in a decrease of the Curie temperature, which correlated with a decrease of \\ the lattice parameter of the $\mathrm{La}(\mathrm{Fe}, \mathrm{Si})_{13}$ - type phase. For samples corresponding to $\mathrm{Mn}$ content $x=0.1$ and 0.2 a \\ decrease of magnetic entropy change was observed. However in the case of the sample with $x=0.3$ an increase of \\ magnetic entropy change was detected.
}

DOI: 10.12693/APhysPolA.133.648

PACS/topics: $75.30 . \mathrm{Sg}, 75.50 . \mathrm{Bb}$

\section{Introduction}

The magnetic cooling based on the magnetocaloric effect (MCE) is an interesting alternative to conventional refrigeration due to its high efficiency $(\sim 60 \%)$ and environmental-friendliness process [1]. The magnetocaloric materials (MCMs), like $\mathrm{Gd}_{5} \mathrm{Si}_{2} \mathrm{Ge}_{2}[2,3]$, MnFeX (where $\mathrm{X}=\mathrm{P}, \mathrm{B}, \mathrm{As}$ ) [4], Ni-Mn-Ga [5] and MnCoGe-based [6] are characterized by structural transformation in the vicinity of $T_{\mathrm{C}}$, which results in high magnetic entropy change $\Delta S_{M}$ and adiabatic temperature change $\Delta T_{a d}$. These alloys are relatively expensive due to the high content of elements such as Gd, Mn or Co. The $\mathrm{La}(\mathrm{Fe}, \mathrm{Si})_{13}$ alloys are an interesting alternative. Relatively high Fe content (almost 80 at.\%) induces low price and metamagnetic first order phase transition, which occurrs in the vicinity of the $T_{\mathrm{C}}$ of $f c c$ pseudobinary $\mathrm{La}(\mathrm{Fe}, \mathrm{Si})_{13}$ phase results in high $\Delta S_{M}$ [7]. For the last decade, the $\mathrm{La}(\mathrm{Fe}, \mathrm{Si})_{13}$ alloys have been modified by lanthanides (i.e. Pr [8], Ce [9]), transition metals (Co [10], Ni [11] or Mn [12]) and metalloids (i.e. Al [13] or Ga [14]). Wang et al [12] have shown that substitution of Fe by Mn causes a decrease in the $T_{\mathrm{C}}$ and $\Delta S_{M}$. This type of alloys is very sensitive on changes of chemical composition and i.e. combination of $\mathrm{Ni}$ and Co induces alteration of negative lattice expansion [11]. The aim of present paper is to study the substitution of Fe by $\mathrm{Mn}$ in the $\mathrm{LaFe}_{11.2} \mathrm{Co}_{0.7} \mathrm{Si}_{1.1}$, which characterizes relatively high $\Delta S_{M}$ at ambient temperature [15].

\section{Experimental method}

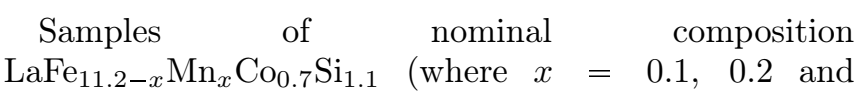

\footnotetext{
*corresponding author; e-mail: pgebara@wip.pcz.pl
}

$0.3)$ were prepared by arc-melting of high purity constituent elements under a low pressure of Ar. Ingots were re-melted several times to ensure their homogeneity. Subsequently specimens were sealed-off in quartz tubes under a low pressure of $\mathrm{Ar}$ and annealed at 1323K for 15 days. The phase constitution was studied using Bruker D8 Advance X-ray diffractometer with $\mathrm{CuK} \alpha$ radiation. The XRD was supported by the Rietveld analysis using the PowderCell 2.4 package [16]. Magnetic properties of the prepared samples were measured in a wide range of temperatures by Quantum Design MPMS-XL 5 equipped with a $5 \mathrm{~T}$ superconducting magnet.

\section{Results and discussion}

The analysis of the XRD patterns indicates that the annealed samples are almost single phase. However, some small amount of $\alpha$-Fe, less than $10 \mathrm{vol} . \%$ was detected in all samples. Results of the Rietveld analysis are collected in Table I. A visible decrease of the lattice constant with the increase of $\mathrm{Mn}$ addition is in contradiction with results published by Wang et al in [12]. They observed a rise of cell parameter with an increase in Mn content. Such different behaviour could be related to the chemical composition of the alloy. Moreover, the successive increase of the $\alpha$-Fe phase was detected with a growth of $\mathrm{Mn}$ and such an effect was observed in [12]. As shown in [10-15], the change of the unit cell parameter induces a variation of the Curie temperature. According to that, the temperature dependences of magnetization were collected for all investigated samples during zero-field cooling regime (Fig.1). A successive decrease of $T_{\mathrm{C}}$ with an increase of Mn addition is clearly seen. The values of $T_{\mathrm{C}}$ equal 241,222 and $198 \mathrm{~K}$ for $x=0.1,0.2$ and 0.3 , respectively. It is well known that the Curie temperature value depends strongly on the Fe-Fe interactions in this type of alloys. The decrease of lattice constant causes a change of distances between Fe atoms and results in the 
weakening of $\mathrm{Fe}-\mathrm{Fe}$ interactions, which is observed as a lowering of $T_{\mathrm{C}}$.

TABLE I

Results of Rietveld refinement carried out for $\mathrm{LaFe}_{11.2-x} \mathrm{Mn}_{x} \mathrm{Co}_{0.7} \mathrm{Si}_{1.1}$ (where $x=0.1,0.2,0.3$ ) $\left(E_{\text {xpected }}=\mathrm{La}(\mathrm{Fe}, \mathrm{Si})_{13}\right.$-type, $P_{\text {arasitic }}=\alpha$-Fe $)$.

\begin{tabular}{c|c|c|c}
\hline \hline $\begin{array}{c}\text { Mn con- } \\
\text { tent } x\end{array}$ & Phase & $\begin{array}{c}\text { Fraction } \\
{[\text { vol.\%] }}\end{array}$ & $\begin{array}{c}\text { Lattice constant } \\
a[\AA]\end{array}$ \\
\hline \multirow{2}{*}{0.1} & $\mathrm{E}$ & 92 & $11.4745 \pm 0.0011$ \\
& $\mathrm{P}$ & 8 & $2.8605 \pm 0.0009$ \\
0.2 & $\mathrm{E}$ & 91 & $11.4708 \pm 0.0012$ \\
& $\mathrm{P}$ & 9 & $2.8607 \pm 0.0011$ \\
0.3 & $\mathrm{E}$ & 90 & $11.4676 \pm 0.0011$ \\
& $\mathrm{P}$ & 10 & $2.8608 \pm 0.0012$
\end{tabular}

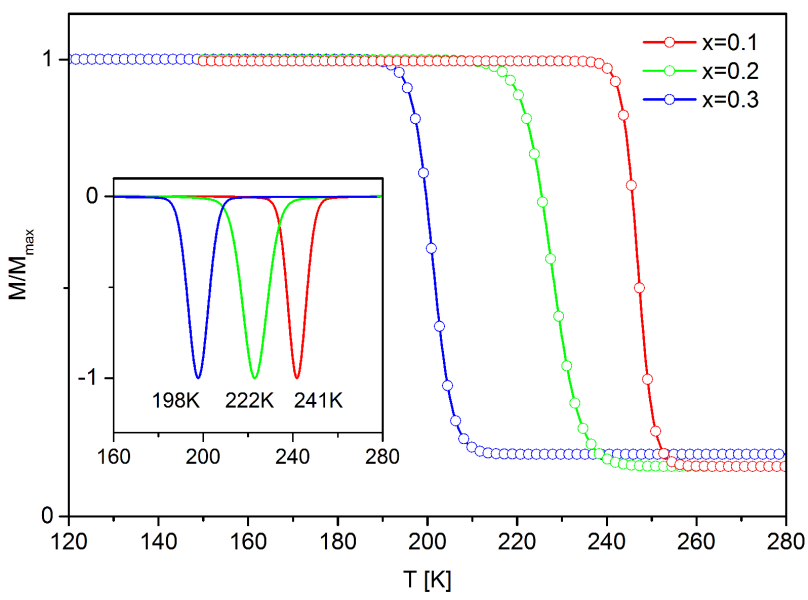

Fig. 1. The $M$ vs. $T$ curves collected for samples with different $\mathrm{Mn}$ content and their first derivatives (inset).

From a magnetic cooling point of view, such tailored decreases of $T_{\mathrm{C}}$ gives an opportunity to get multi-step magnetic regenerator working in a wide range of temperatures. However, it is important to reveal the $\Delta S_{M}$ vs. $T$ curves for each alloy. The $M$ vs. $H$ dependences were measured in a wide range of temperatures. The $\Delta S_{M}$ values were calculated using the well-known thermomagnetic Maxwell relation:

$$
\Delta S_{M}(T, H)=\mu_{0} \int_{0}^{H}\left(\frac{\partial M(T, H)}{\partial T}\right)_{H} \mathrm{~d} H .
$$

where: $M$ is magnetization, $\mu_{0}$ is magnetic permeability of vacuum and $H$ is magnetic field.

The $\Delta S_{M}$ vs. $T$ curves determined for all studied specimens are depicted in Fig. 2. The highest values of $\Delta S_{M}$ reached 14.93, 12.34 and 14.54 were detected in samples with $x=0.1,0.2$ and 0.3 , respectively. Obtained values of $\Delta S_{M}$ are lower than those shown in [15] for base $\mathrm{LaFe}_{11.2} \mathrm{Co}_{0.7} \mathrm{Si}_{1.1}$ alloy and these presented by Yan et al. in [10]. Such behavior suggests that Mn addition causes weakening of itinerant electron metamagnetic transition and it results in decrease of $\Delta S_{M}$. Moreover, Wang et al [12] and Krautz et al [17] observed a systematic decrease of $\Delta S_{M}$ with an increase of $\mathrm{Mn}$ addition. Our results partially confirm their studies, due to the fact that for sample $\mathrm{x}=0.2$ the decrease of $\Delta S_{M}$ compared to the alloy with $x=0.1$ is shown. However, the significant increase of $\Delta S_{M}$ for the specimen with $\mathrm{x}=0.3$ is found. As shown in [10-15], the decrease of $\Delta S_{M}$ was attributed to the weakening of the itinerant electron metamagnetic (IEM) transition with an increase of alloying additions. However, we observed two effects of weakening and strengthening the IEM transition for samples with $x=0.2$ and $x=0.3 \mathrm{Mn}$ content, respectively. Such behaviour confirms the prediction that properties of the $\mathrm{La}(\mathrm{Fe}, \mathrm{Si})_{13}$ phase are strongly related to the chemical composition.

The relative cooling power $(R C P)$ has been calculated using the following relation [18]:

$$
R C P=-\Delta S_{M \max } \delta T_{F W H M},
$$

where: $\delta T_{F W H M}$ is temperature of thermodynamic cycle (full width at half maximum of $\Delta S_{M}$ vs. $T$ curve).

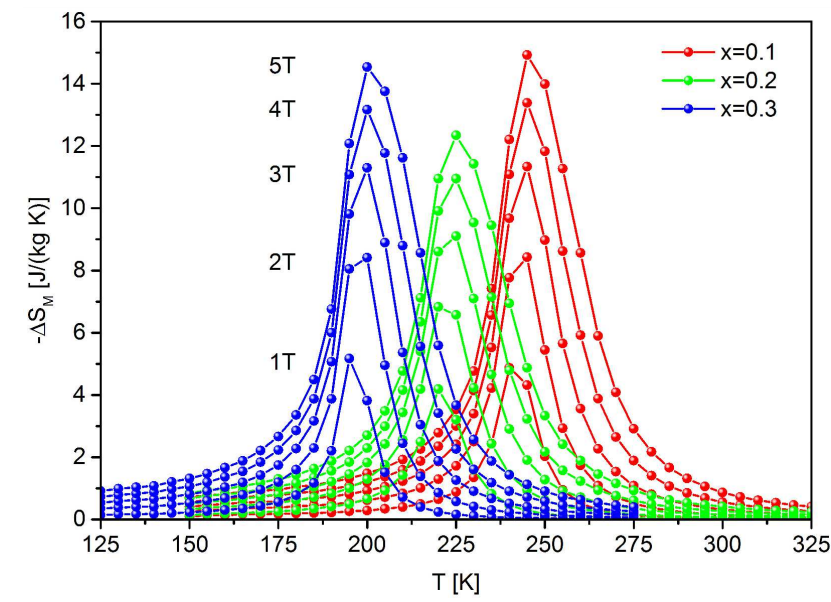

Fig. 2. The temperature dependences of magnetic entropy change determined for all investigated samples.

The $R C P$ and $\delta T_{F W H M}$ values have been collected in Table II.

TABLE II

The $\Delta S_{M}, R C P$ and $\delta T_{F W H M}$ values collected for investigated alloys.

\begin{tabular}{c|c|c|c|c|c|c}
\hline \hline $\begin{array}{c}\text { Mn con- } \\
\text { tent } x\end{array}$ & \multicolumn{2}{|c|}{0.1} & \multicolumn{2}{c|}{0.2} & \multicolumn{2}{c}{0.3} \\
\hline$\mu_{0} H[\mathrm{~T}]$ & 2 & 5 & 2 & 5 & 2 & 5 \\
\hline$-\Delta S_{M}[\mathrm{~J} /(\mathrm{kg} \mathrm{K})]$ & 8.43 & 14.93 & 6.83 & 12.34 & 8.41 & 14.54 \\
$\delta T_{F W H M}[\mathrm{~K}]$ & 18 & 28 & 20 & 30 & 15 & 26 \\
$R C P[\mathrm{~J} / \mathrm{kg}]$ & 151 & 418 & 130 & 358 & 126 & 377
\end{tabular}

As shown in Table II, the $\delta T_{F W H M}$ increases for the sample with Mn content $x=0.2$ and it was observed in $[12,17]$. However, for the specimen with $\mathrm{x}=0.3$, a visible decrease is revealed. Moreover, the $\delta T_{F W H M}$ values are comparable with results showed by Wang et al [12]. 
The highest RCP has been noticed in the sample with $x=0.1$. The RCP values determined in this study are almost two times lower than those delivered by Fujieda et al. [19]. However, Fujieda et al. [19] studied the Ce doped samples and this atom causes an increase in the magnetic entropy change, due to the nonzero magnetic moment. In order to reveal the nature of the magnetic phase transition, the $M^{2}$ vs. $H / M$ isotherms (Arrott plots) have been constructed in the vicinity of the Curie temperature (Fig. 3). The positive slope, observed for samples with $\mathrm{Mn}$ content $x=0.1$ and 0.2 , suggests a second order phase transition nature according to the Banerjee criterion [20]. However, the slight "s-shape" of the Arrott plots at temperatures just above the Curie point is visible for the sample with the highest content of Mn. Such a shape of Arrott plots could suggest the occurrence of first order metamagnetic phase transition in this sample $[10,12]$. In order to confirm these predictions, more advanced analysis of phase transition nature is required using the Landau theory or scaling method and will be done in further studies of these alloys.
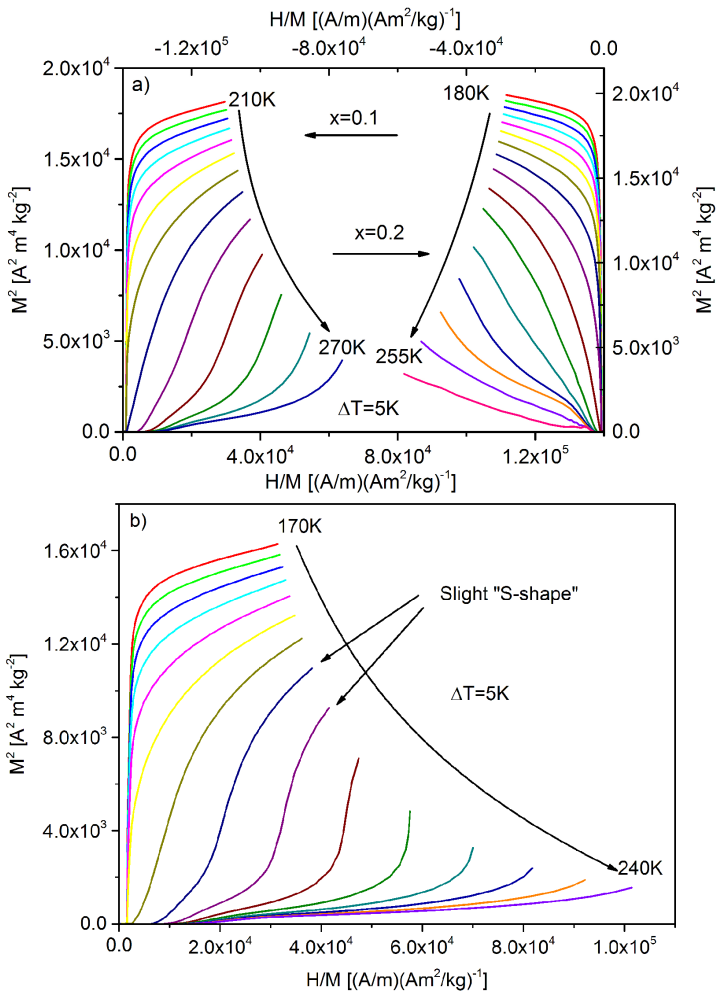

Fig. 3. The $\mathrm{M}^{2}$ vs. H/M isotherms (Arrott plots) constructed for samples with Mn content $x=0.1$ and $0.2(\mathrm{a})$ and $x=0.3(\mathrm{~b})$.

\section{Conclusions}

In this paper the influence of partial substitution of $\mathrm{Fe}$ by $\mathrm{Mn}$ in the $\mathrm{LaFe}_{11.2-x} \mathrm{Mn}_{x} \mathrm{Co}_{0.7} \mathrm{Si}_{1.1}$ was studied. The successive contraction of the lattice constant with an increase of Mn content was observed, which induces the decrease of the Curie temperature. Moreover, the increase of $\mathrm{Mn}$ content $(x=0.1$ and 0.2$)$ causes the decrease in magnetic entropy change compared to base alloy, which is attributed to the weakening of the IEM phase transition. However, an increase of $\Delta S_{M}$ is noticed for the sample with $x=0.3$, which suggests the strengthing of the IEM transition. Such different behaviour was confirmed by contructing Arrott plots. A monotonic positive slope was observed for samples $x=0.1$ and 0.2 . However, a slight "s-shape" was detected for the specimen with the highest Mn addition, which can suggest the occurrence of weak first order in the IEM transition.

\section{Acknowledgement}

This work was supported by the projects APVV-150621 and ITMS 26220220061. P.G. would like to thank the Slovak Academic Information Agency SAIA and Head of Institute of Physics Częstochowa University of Technology prof. R. Szczęśniak for financial support.

\section{References}

[1] A.M. Tishin, Y.I. Spichkin, The magnetocaloric effect and its application, Institute of Physics Series in Condensed Matter Physics, 2003.

[2] V.K. Pecharsky, K.A. Gschneidner Jr., Phys. Rev. Lett. 78, 4494 (1997).

[3] M. Hasiak, Phys. Stat. Sol. A, 1 (2016).

[4] P. Włodarczyk, L. Hawelek, M. Kowalczyk, M. Kamińska, P. Zackiewicz, M. Polak, M. Hreczka, A. Kolano-Burian, Solid State Sci. 56, (2016).

[5] J. Ferenc, M. Kowalczyk, R. Wróblewski, G. Cieślak, K. Sielicki, M. Leonowicz, T. Kulik, Acta Phys. Pol. A 128, 111 (2015).

[6] H. Zhang, Y. Li, E. Liu, K. Tao, M. Wu, Y. Wang, H. Zhou, Y. Xue, C. Cheng, T. Yan, K. Long, Y. Long, Mater. Design 114, 531 (2017).

[7] A. Fujeida, A. Fujita, K. Fukamichi, Appl. Phys. Lett. 81, 1276 (2002).

[8] J. Shen, Q.Y. Dong, Y.X. Li, J.R. Sun, J. All. Comp. 458, 115 (2008).

[9] A. Fujita, S. Fujieda, K. Fukamichi, J. Magn. Magn. Mat. 310, e1006 (2007).

[10] A. Yan, K.H. Muller, O. Gutfleisch, J. All. Comp. 450, 18 (2008).

[11] P. Gębara, P. Pawlik, M. Hasiak, J. Magn. Magn. Mat. 422, 61 (2017).

[12] F. Wang, Y.F. Chen, G.J. Wang, B.G. Shen, J. Phys D Appl. Phys. 36, 1 (2002).

[13] P. Gebara, P. Pawlik, B. Michalski, J.J. Wyslocki, Acta Phys. Pol. A 127, 576 (2015).

[14] P. Gebara, P. Pawlik, B. Michalski, J.J. Wyslocki, K. Kotynia, Acta Phys. Pol. A 128, 87 (2015).

[15] F.X. Hu, B.G. Shen, J.R. Sun, G.J. Wang, Z.H. Cheng, Appl. Phys. Lett. 80, 826 (2002).

[16] W. Kraus, G. Nolze, PowderCell 2.4, D-BAM 12205, Berlin 2002.

[17] M. Krautz, K. Skokov, T. Gottschall, C.S. Teixera, A. Waske, J. Liu, L. Schultz, O. Gutfleish, J. All. Comp. 589, 27 (2014)

[18] K.A. Gschneidner Jr., V.K. Pecharsky, Annu. Rev. Mater. Sci. 30, 387 (2000).

[19] S. Fujieda, A. Fujita, N. Kawamoto, K. Fukamichi, Appl. Phys. Lett. 89, 062504 (2006).

[20] S.K. Banerjee, Phys. Lett. 12, 16 (1964). 